\title{
Patronagem, Clientelismo e Redes Clientelares: a aparente duração alargada de um mesmo conceito na história política brasileira ${ }^{1}$
}

\author{
Alexandre Mendes Cunha*
}

\begin{abstract}
Resumo:
O texto reflete sobre a reiteração do fenômeno do clientelismo na história política brasileira. Discute-se de forma crítica com a historiografia a aparente duração alargada desse fenômeno desde o período colonial à história republicana. $\mathrm{O}$ ponto fundamental, não obstante, é a percepção do que ao longo do tempo vai se diferenciando nessas relações, de maneira que preserve o essencial de sua função política ante um contexto político, social e econômico marcadamente assimétrico. Duas dimensões de análise, por fim, são sugeridas para se acompanhar essa diferenciação do fenômeno clientelístico ao longo do tempo, as formas da racionalidade econômica e da cultura política.
\end{abstract}

Palavras-chave: relações clientelísticas, historiografia, história política.

O tema da patronagem política, ou, ainda, da leitura da conformação dos espaços da política a partir de relações privadas de cunho clientelístico, vem sendo apresentado pela historiografia como elemento distintivo não de um, mas de variados períodos da história política brasileira. $\mathrm{Ou}$, ainda, em outro registro, como traço essencial da própria cultura política de mais de um contexto histórico. Neste sentido, linha que alguns autores chegam mesmo a reforçar, a patronagem e o clientelismo - ou, em outro acento, o próprio patrimonialismo - assumem as vestes de um fenômeno perene na política brasílica. O objetivo aqui é refletir criticamente sobre essa reiteração ou repetição do fenômeno e demarcar algumas questões que se mostrem pertinentes à análise dos atores políticos, e das relações que delineavam e orientavam sua ação social, nos espaços políticos da América portuguesa, depois Brasil, entre os séculos XVIII e XIX.

Para se desdobrar o argumento, será dado destaque aqui à discussão das chamadas "redes clientelares", tema recorrente na historiografia política recente do período colonial brasileiro, buscando sua articulação com o tema da patronagem e do clientelismo na historiografia do período imperial e da primeira república, por onde o texto se inicia. Tomando em conjunto, portanto, as redes clientelares que, para certo conjunto de autores, representam marca essencial das configurações de poder no antigo 
regime português e, em extensão, nas colônias, com as leituras classicamente estabelecidas da patronagem e variações para os séculos XIX e começo do XX na história política brasileira, estaríamos diante de um fenômeno efetivamente de amplitude secular, o que em si merece ser discutido com profundidade.

A reiteração ou pura repetição desse tipo de relação assimétrica de poder no tempo, dando forma ao fenômeno geral da patronagem e do clientelismo, claramente ultrapassa a curta duração, o acontecimento, inserindo-se em um tempo histórico que, se não é o da história de respiração muito contida, da longa ou longíssima duração, na expressão conhecida de Fernand Braudel, é sem dúvida o de um tempo bastante alargado. A aproximação do tema aqui proposto com a reflexão do tempo histórico nascida na Escola dos Annales em diálogo com o estruturalismo é interessante justamente porque leva a se inquirir logo de saída se este fenômeno clientelístico assume ou não um traço estrutural na dinâmica política brasileira, resultando assim em sua amplitude secular. ${ }^{2}$ A resposta que se propõe é que essa amplitude secular existe sim na superfície do fenômeno, em sua aparência instrumental, mas que no fundamental, não obstante, o fenômeno assume matizes bastante diversos ao longo do tempo. Esse acento clientelístico de duração alargada na história política brasileira, na perspectiva que aqui vai se defender, é algo que, se na sua superfície assume certa imutabilidade de feições, fruto de outro aspecto, este sim, estrutural de nossa realidade — a desigualdade sócio-econômico-cultural —, uma série de seus elementos constitutivos, no entanto, vão se alterar com o passar do tempo, fazendo que uma análise criteriosa da questão tenha de se concentrar justamente nesses pontos diversos que garantem a reiteração desse fenômeno político sob a mesma roupagem aparente.

Finalmente, vale acrescentar que a base da presente reflexão é um diálogo estreito com a historiografia, muito embora o fundamental da reflexão seja mais propriamente uma análise de cunho teórico-conceitual que um balanço historiográfico, uma vez que interessa exatamente pensar a adequação histórica e a propriedade analítica de algumas categorias próprias do debate da história política do período em questão, e que não raro são utilizados de forma algo inadvertida.

\section{A reiteração da patronagem e suas linhagens na historiografia política brasileira}


As clássicas “interpretações” do Brasil que vêm à cena nos anos trinta do século passado lançam luzes sobre a distância abissal que separaria a estrutura social de matriz patriarcal originária do período colonial das instituições liberal-democráticas que assomam no horizonte político a partir do século XIX. De forma ampla nessas leituras, seria o "iberismo", 3 marcado pelo acerbo peso das tradições, que estaria na base da dificuldade de se implementarem normas abstratas aqui por estas terras. Isto deu espaço a uma interpretação particular do desenvolvimento brasileiro, o que, a partir de certo viés da sociologia da modernização, constituiria a matriz explicativa para o "atraso" da sociedade brasileira. Esse atraso seria assim resultante da "herança do patrimonialismo ibérico, cujas estruturas teriam sido ainda mais reforçadas com o transplante, no começo do século XIX, do Estado português no solo americano". ${ }^{4}$ O contraste entre a tradição e a mudança, entre a conservação e certa abertura ao novo, seria para além disto, e obviamente de forma refratária a qualquer segmentação simplista, a base da própria organização das facções políticas e orientações do discurso na política imperial, como ainda se terá oportunidade de discutir no presente texto.

A questão da permanência de uma herança que restringe a ampliação da participação no jogo político, e mesmo de esquemas mentais que permitem uma incorporação particular de certo repertório de idéias políticas que toma forma com as revoluções democrático-burguesas, encontra, para certo conjunto desses intérpretes do Brasil, na obra de Max Weber, alguns de seus elementos centrais, mesmo que, para alguns deles, o peso de um patrimonialismo quase a-histórico faça que a conformação de certas estruturas políticas modernas não chegue a produzir equivalente modernização política, através da obliteração de arcaísmos e da superação paulatina do horizonte de "atraso". O resultado tende a ser o de longos percursos e pouco avanço, em "viagens redondas", como coloca Raimundo Faoro.

O patrimonialismo é sem dúvida o eixo predileto dessas leituras, o que marca uma arraigada e clássica interpretação do que se define por "formação social brasileira", fazendo, no entanto, multiplicar categorias em que pouco a pouco pesquisas históricas mais aprofundadas viriam a mostrar certa inadequação. $O$ peso de grandes esquemas teóricos não deixaria ainda de turvar a visão para o específico da formação histórica brasileira, sendo as análises que insistiram em uma leitura "feudalista" do período colonial brasileiro, como em Nestor Duarte, ${ }^{5}$ um exemplo flagrante disto. O pano de fundo teórico desses esquemas encontra-se em certo aspecto distintivo das obras de Karl Marx e Max Weber acerca da evolução das sociedades ocidentais e na apropriação 
particular que desses esquemas se fez no contexto do pensamento social brasileiro. Para Marx essa seqüência evolutiva seria marcada pela transição fundamental "feudalismocapitalismo", sendo que para Weber caberia uma certa derivação, o patrimonialismo, em Marx restrito ao modo asiático de produção. ${ }^{6} \mathrm{O}$ patrimonialismo assoma assim para certo conjunto de autores de inclinação weberiana como a marca do desenvolvimento social e econômico brasileiro em associação genérica com o desenvolvimento político e as formas de dominação próprias das sociedades orientais estudadas por esse autor.

O desenvolvimento econômico, social e político brasileiro estaria dessa forma marcado pela forte presença do patrimonialismo, que ao momento da formação do Estado no século XIX responde pela atrofia do desenvolvimento de uma sociedade civil, à feição do modelo inglês, base da organização liberal-democrática. Essas leituras weberianas, não obstante, assumiriam, segundo apresentação empreendida por Luiz Werneck Viana, dois conjuntos de posições, fazendo: 1) pesar no Estado a marca dessa dominação patrimonial, ou 2) lendo o patrimonialismo na ação social de atores privados. $^{7}$

A primeira versão tem como seu intérprete essencial Raimundo Faoro, que faz aproximar a forma patrimonial do Estado brasileiro, por meio da tradição ibérica, às formas políticas do oriente analisadas por Weber. Segundo Werneck Vianna, "Raimundo Faoro, no seu clássico Os Donos do Poder, além de avizinhar o iberismo do despotismo oriental, retomando o argumento de Tavares Bastos e Sarmiento, ${ }^{8}$ sugere a necessidade, motivado pelo seu estudo de caso, de se proceder à revisão da tese de Weber, que vincula a emergência do espírito capitalista à ética calvinista, em favor da que sustenta que 'somente os países revolvidos pelo feudalismo teriam chegado a adotar o sistema capitalista, integrando nele a sociedade e o Estado". 9 A esta mesma linha pertenceria também o trabalho de Simon Schwartzman, Bases do Autoritarismo Brasileiro, que reforça os traços dessa leitura weberiana de uma dominação tradicional, patrimonialista, ao caso brasileiro; sendo que fazem ambos os textos, desenhar aqui, ainda segundo Werneck Vianna, "um sistema político de cooptação sobreposto ao de representação, uma sociedade estamental igualmente sobreposta à estrutura de classes, o primado do Direito Administrativo sobre o Direito Civil, a forma de domínio patrimonial-burocrática e o indivíduo como um ser desprovido de iniciativa e sem direitos diante do Estado". 10

A segunda versão do patrimonialismo brasileiro inverte o foco do Estado para a sociedade e busca compreender nos termos da dominação de base senhorial 
empreendida no contexto agrário a trama da sociabilidade que envolve indivíduos submetidos à situação de dependência pessoal. O texto de Maria Silvia de Carvalho Franco, Homens Livres na Ordem Escravocrata, é o principal responsável por esse tipo de leitura do patrimonialismo que recrudesce na formação peculiar do Estado brasileiro, ao investigar as efetivas condições em que se articula o aparelho burocrático desse Estado. Maria Silvia de Carvalho Franco, novamente segundo Werneck Vianna:

ao utilizar o argumento de Weber sobre a singularidade da organização burocrática estatal no Ocidente moderno, demonstra empiricamente como, aqui, nas condições de escassez de recursos que pudesse suportar a ação do Estado, o processo de expropriação do servidor público dos meios materiais da administração teria sido apenas formal, na medida em que, na realidade, boa parte desses meios era financiada com recursos privados. Foi a pobreza da agência estatal, e não a sua natureza pretensamente quase oriental, que teria dado como resultado não desejado a fusão entre o público e o privado, permitindo, assim, que o exercício do poder originário do cargo público pudesse ser traduzido na busca de fins estritamente particulares. ${ }^{11}$

A esta ordem escravocrata que se mantém ante a formação do Estado e mesmo na incorporação particular de idéias políticas liberais, não seriam mesmo poucas as contradições, sendo estas altamente reveladoras da particular fusão que persiste pelo século XIX entre as dimensões do público e do privado. A Independência instaura neste sentido, como se sabe, um dilema ao constituir um Estado soberano e ao mesmo tempo manter a escravidão. Com isso, o Estado, que seria na definição clássica de Weber o monopólio da violência legítima, encontra uma sociedade que por conta da escravidão tem de se organizar sobre a violência privada dos senhores contra seus escravos. ${ }^{12}$

Entre os extremos desse debate acerca do espaço político analisado por esses diversos intérpretes da "formação" histórica brasileira, insere-se uma obra mais recente e de grande interesse à questão aqui perseguida. Exatamente esse território político marcadamente indistinto entre o poder público e o privado é o mote do livro Clientelismo e politica no Brasil do século XIX, de Richard Graham. ${ }^{13}$ Trabalho importante para a análise da política no período imperial brasileiro, sendo mesmo o principal responsável por insistir na idéia que logo de início se anunciou e se inquiriu aqui: a duração alargada das relações clientelíticas na sociedade brasileira. Graham nesse livro segue, quase que em homenagem a um autor fundamental aos seus anos de formação (como revela logo à primeira página do prefácio), a metodologia de investigação da monumental obra de Sir Lewis Namier $^{14}$ dedicada ao estudo de clientelas políticas na Inglaterra do século XVIII. O estudo prosopográfico de elites 
políticas ao longo do século XIX, com detida análise do processo eleitoral no Império, palco em que se revelam intensamente as relações clientelísticas, é o fio condutor do estudo de Graham, bem como dimensão essencial do The Structure of Politics at the accession of George III, de Namier; sendo, aliás, "As estruturas da política” o título do primeiro capítulo do livro de Graham.

Graham parte das bases de uma organização social patriarcal para vislumbrar o peso dessas ligações nas cadeias de dependência e subordinação que aí se articulam, dando corpo à hierarquia social do Império brasileiro, e percebendo que a partir de 1840 demarca-se justamente a ascendência do grupo de proprietários ao controle do Estado. ${ }^{15}$ Por isso, a associação direta com $O$ tempo saquarema, de Ilmar Rohloff de Mattos ${ }^{16}$, cuja linha argumentativa é endossada por Graham em outro de seus escritos:

Talvez o argumento mais criterioso e provocativo sobre as origens da coesão nacional do pós-independência venha de Ilmar Rohloff de Mattos, que procura demonstrar como interesses de classes se ligavam especificamente ao poder de estado. Mattos se concentra no período de meados da década de 1830 até o início da década de 1860 e postula um bloco de fazendeiros de café recentemente enriquecidos, da região do Rio de Janeiro, liderados por um pequeno grupo de políticos/estadistas ativos, ou saídos daquele bloco ou ligados a ele por laços de casamento, esforçando-se com sucesso para absorver líderes de outras regiões, formando uma classe única. Esta classe se definia por sua oposição a outras classes, especialmente aos escravos, mas também à plebe urbana rude e inquieta. Essa classe senhorial abraçou uma ideologia da ordem desenvolvida e defendida por advogados, juízes, jornalistas, professores, médicos, empresários, políticos e burocratas, isto é, os "intelectuais orgânicos", como Antônio Gramsci os chamaria. Através do próprio processo de formação de uma classe poderosa que dominava todo o Brasil, emergiu um forte estado centralizado. Mattos entende esse estado não como simplesmente um aparato coercitivo, mas como um instrumento de orientação intelectual e moral. Por meio do estado, a classe senhorial construiu sua própria unidade e expandiu seu poder, tanto horizontalmente, por todo o território brasileiro, quanto verticalmente sobre maiores segmentos da população livre, não principalmente impondo submissão, mas incorporando esses grupos à "civilização". 17

Não obstante, Graham, ainda que subscrevendo muito da essência das considerações de Ilmar Mattos, insiste em certos acentos diferenciados para algumas questões. Basicamente a preocupação está em refutar a perspectiva de um processo de cooptação das elites para que aceitem uma autoridade central que extrapole o espaço do 
Rio de Janeiro; segundo Graham, os fazendeiros e homens ricos das cidades de regiões variadas do país foram agentes nesse processo de centralização. ${ }^{18}$ Dessa forma, a centralização não se dá por uma imposição da Corte para o campo, mas vai se consumando com base em uma ativa participação política em todos os níveis. Tem-se, portanto, um quadro em que "os políticos na capital ao mesmo tempo assentiam aos interesses dos proprietários em lugarejos de todo o país e asseguravam que as elites locais transmitissem suas opiniões até mesmo ao presidente do Conselho de Ministros". 19

A estruturação desse sistema, não obstante, se fazia a partir do controle eleitoral, que por sua vez tinha como base relações clientelistas na troca de empregos por votos, sendo exatamente este o mecanismo que Graham busca desvelar.

Há que se destacar, não obstante, nas tramas desse processo eleitoral estudado por Grahan, a dimensão litúrgica que o envolve. Estes aspectos são analisados no capítulo "O Teatro das Eleições" de seu livro em questão, o qual cuida de apresentar as eleições como um momento em que são reiteradas naquela sociedade as hierarquias sociais, o que traduz o papel que as regras de etiqueta assumem como dimensão essencial na organização e distinção social. Na forma apresentada pelo autor, em tudo se pode avaliar este quadro como uma permanência do antigo regime, tal qual na rígida composição dos papéis na "figuração" social de que fala Norbert Elias em seu $A$ sociedade de corte, ${ }^{20}$ ainda que, não é nada ocioso lembrar, informada e mediada por significados diversos dos que se apresentariam ao Brasil na segunda metade do século XIX.

Vale destacar, ainda, que o argumento de Graham evolui para demonstrar como as lealdades pessoais dispostas nas cadeias de dependência clientelística organizam em boa medida as próprias divisões políticas, o que caracterizaria no limite um quadro de inexistência de partidos ideológicos no Império. Aí novamente a reposição do modelo de Namier, que tem como tese central de seu livro a inexistência de clivagens partidárias com segmentações ideológicas na trama de interesses privados por ele desvelada para o parlamento inglês nos Setecentos. Esse sistema partidário serviria, portanto, para Graham, especialmente, para "facilitar a comunicação intra-elite e para operar as vitórias eleitorais e a aquisição de cargos". O autor sustenta essa tese com base na avaliação de que questões mais amplas e controversas, como escravidão, imigração, terras e federalismo, tiveram por fim não clivagens partidárias, mas clivaram mesmo os próprios partidos nos debates políticos em fóruns diversos. ${ }^{21}$ 
Ainda de volta ao debate sobre a formação do Estado, a linha argumentativa de Graham, em associação à de Ilmar Mattos, guarda distancia da leitura de José Murilo de Carvalho uma vez que não corrobora a idéia de uma autonomia da elite imperial, possível a partir da formação comum em leis que esta obtivera, o que resultaria em certa independência de perspectivas em relação ao grupo dos fazendeiros. ${ }^{22}$ Por sua vez, a crítica deste autor ao trabalho de Graham é a de que nele os conceitos são tratados de forma pouco consistente. Em primeiro lugar questiona a própria tese da hegemonia e do predomínio dos senhores de terra sobre o Estado, que, como se argumentou acima, reforça a tese de Mattos. Carvalho insiste que, "a vida dos gabinetes, segundo Graham, dependia tanto, se não mais, dos líderes locais do que o oposto. Como para esse autor qualquer concepção de Estado que não implique a dominação de uma classe é abstração teórica ou, pelo menos, inaplicável ao Brasil, só lhe resta postular o domínio da política imperial pela classe dominante rural". ${ }^{23}$ Mais contundentemente, entretanto, argumentaria Carvalho que:

O problema conceitual surge quando Graham trabalha o tempo todo com a noção de clientelismo, de relações patrão-cliente. O clientelismo seria a marca do sistema político imperial. (...) Ora, qualquer noção de clientelismo implica troca entre atores de poder desigual. No caso do clientelismo político, tanto no de representação como no de controle, ou burocrático, para usar distinção feita por Clapham (1982), ${ }^{24}$ o Estado é a parte mais poderosa. É ele quem distribui benefícios públicos em troca de votos ou de qualquer outro tipo de apoio que necessite. O senhoriato rural seira a clientela do Estado. Não é certamente esta a visão de Graham sobre a relação de poderes. Seria mais lógico para ele considerar o Estado como clientela do senhoriato. Mas não há nada em seu texto justificando essa reviravolta no conceito de clientelismo". ${ }^{25}$

Não me parece que nesta crítica Carvalho faça de todo justiça às idéias de Graham. O viés assumido por Carvalho para pensar a noção de clientelismo subtrai exatamente o aspecto nevrálgico do argumento de Graham ao pressupor algo no Estado de esfera pública autônoma ou, minimamente, a existência efetiva de uma esfera pública autônoma. Ainda que Graham não se enverede por essa discussão, sua matriz para apresentar as relações clientelísticas no Império é a da exacerbação do personalismo nessa sociedade e assim da indistinção persistente das esferas do público e do privado. Neste sentido, ainda que obviamente as relações do tipo patrão-cliente se refiram a dependências estabelecidas entre atores de forças desiguais, o político de gabinete do Império não necessariamente representa, ainda que se valha diretamente dos ganhos daí decorrentes, o peso impessoal do Estado, e, ao estabelecer vínculos de dependência com 
grupos em ascensão econômica como o de certos fazendeiros, não faz de forma direta o Estado cliente desses. A própria noção de Estado a este período tem de ser mesmo tratada com redobrado cuidado sempre, e o argumento de Graham é tanto mais válido quanto se esforce para vê-lo como uma arqueologia das práticas e comportamentos dos atores políticos em um contexto ainda de formação dessas estruturas modernas do Estado, respondendo ao ideário liberal-democrático ante permanência de outras formas de organização e afirmação do poder e da autoridade, formas próprias, como se verá aqui, do antigo regime. Neste sentido não se trata mais das redes clientelares que são entes centrais da conformação de poder no antigo regime, mas também não se trata ainda da relação clientelística que marcaria o contexto da República Velha (talvez mais perto do tom da análise de Carvalho ao trabalho de Graham), exemplarmente analisada por Victor Nunes Leal em seu Coronelismo, Enxada e Voto, ${ }^{26}$ no qual o "Estado" assume a dimensão impessoal de ator político na barganha clientelística com o grupo dos coronéis, que por sua vez fazem pesar a dimensão personalística de seu poder local (traços das permanência mencionada acima), por sobre as comunidades sob sua influência direta.

Uma outra crítica ao livro de Graham, todavia, parece mais pertinente para introduzir os desdobramentos a que se propõe este texto. Angela Alonso, em uma competente avaliação dessa obra, após ressaltar suas várias qualidades, argumenta que:

(...) a recusa de um movimento contínuo e positivo de mudança leva Graham a assumir a patronagem como fenômeno de longa duração e, neste sentido, como grande motor explicativo não apenas do Império, mas de toda a história brasileira: "O sistema de protetores e clientes não representa um 'estágio' na história do Brasil, a não ser no sentido de que serviu aos interesses de uma classe cuja vida se espera não seja eterna" (p. 347)

Sendo que o problema daí decorrente é que:

Este tratamento induz o leitor a pensar a patronagem como uma peculiaridade ibérica, um traço cultural — como diz a orelha da edição brasileira —, o que está longe de ser verdade. Padrões similares aos descritos por Graham podem ser detectados nesse período tanto nos Estados Unidos quanto na própria Inglaterra - o grande modelo liberal do século XIX —, o que, aliás, não passava despercebido aos políticos do Império." 28

Esta crítica aponta efetivamente para uma continuidade aventada, mas pouco refletida no livro de Graham. O ponto de vista aqui defendido, não obstante, é diverso do argumentado por Alonso. Ainda que ao livro de Graham o clientelismo culmine, por fim, no espaço difuso de uma prática perene na política brasileira, fruto de um traço 
cultural não analisado de forma clara no trabalho, entende-se aqui que o clientelismo não pode ser tomado como um sistema político específico e datável porque fruto de conjuntura também específica, como certamente é o caso, por exemplo, do “coronelismo". As relações clientelísticas têm eminentemente duração maior, maior pluralidade de casos e é informada por um número infindo de condicionantes ao longo do tempo na trilha das relações de dependência conformadas entre atores de força desigual. Daí que o desafio, para não se perder em um relativismo total que faz a dimensão efetivamente histórica sucumbir ante um dado aparentemente imutável, é o de ver não o que permanece inalterado, mas o que neste fenômeno vai ao longo do tempo se tornando diverso. O esforço aqui é, neste sentido e como já se anunciou logo no início do texto, o de esboçar algumas dimensões possíveis de análise dos quadros da história brasileira, com vistas a apreender o que progressivamente vai diferenciando esse traço clientelístico de amplitude secular, que, ao mesmo tempo em que faz diverso o fenômeno das redes clientelares no início do século XVIII do coronelismo no começo do XX, faz que este se reproduza em seu essencial como forma de preservar a continuidade de certa estrutura desigual e a permanência de grupos sociais específicos na condição de elites econômicas e políticas.

A perspectiva aqui defendida é que duas dimensões em especial, mesmo que não exclusivamente, podem oferecer uma guia consistente para começar a perseguir o que vai se tornando diverso no fenômeno clientelístico no período tratado: as formas da racionalidade econômica e as culturas políticas.

\section{Racionalidade econômica e cultura(s) política(s)}

A reflexão sobre o campo específico da economia reserva grande interesse para a compreensão das relações clientelísticas, uma vez que lança os olhos diretamente para as motivações materiais subjacentes às relações analisadas, bem como, especialmente, para se avaliar a racionalidade própria dos atores sociais, uma vez inseridos em mercados pré-capitalistas ou já imersos em relações propriamente capitalistas de produção. Mais ainda, ajuda a pensar, o que é sobremaneira relevante para o caso brasileiro nos séculos XVIII e XIX, a mudança progressiva dessa racionalidade e do significado dos ganhos materiais ante ganhos simbólicos em conjunturas de progressiva mas lenta transformação da formação econômico-social, ante a permanência de 
estruturas de poder próprias de outros contextos, da qual a escravidão no Dezenove é eloqüente exemplo.

A economia, enquanto dimensão da vida e atividades humanas, guardaria antes da efetiva ampliação do capitalismo significados próprios e eminentemente mais amplos. A oeconomia, como se sabe, é uma dimensão própria da moral clássica, junto da iustitia e da moral monastica. ${ }^{29}$ Nos quadros mentais do antigo regime português, ante uma mais ampla sobrevivência de concepções orientadas pelo tomismo no corpo da Segunda Escolástica, o que se verifica é que o entendimento da esfera econômica permaneceria enormemente marcado pelos ensinamentos de Aristóteles, para o qual esta só se faz legítima se submetida a preceitos éticos e subordinada ao "bem comum". Disto é que decorre o tema da justiça distributiva como dimensão essencial da esfera econômica aos quadros do antigo regime. ${ }^{30} \mathrm{O}$ clássico estudo de Edward. P. Thompson, por exemplo, tratando dos motins de fome na Inglaterra pré-Revolução Industrial no século XVIII, inseridos em uma leitura da "economia moral das multidões", faz colocar em destaque o tema de uma concepção própria de economia e direito nesses contextos, eminentemente informada por outras racionalidades que não a capitalista. ${ }^{31}$

A contribuição da antropologia, por outro lado, foi crucial para expor que nem a economia nem tampouco o mercado têm necessariamente em todas as sociedades a centralidade que possuem na sociedade capitalista. Os ensinamentos de Karl Polányi em seu clássico A grande transformação, bem como em outros trabalhos, contribuem exemplarmente para explicitar que a motivação do lucro individual a partir de trocas mercantis não teve, até a era moderna, lugar dominante na vida econômica, o que é base para a diferenciação entre "sociedade com mercado" e o que vem a ser a "sociedade de mercado", na qual teria lugar exemplarmente a mercantilização ampla, mesmo das relações sociais, no que Marx tomaria por fetichismo da mercadoria. ${ }^{32}$ Mais ainda, tratase da compreensão de diversas motivações não-mercantis para a troca, em contextos sociais e históricos diversos, como nos conceitos de reciprocidade, dádiva, parentesco, retribuição, vizinhança, entre outros. ${ }^{33}$ De grande importância é a menção neste particular à obra de Marcel Mauss, ou ainda Maurice Godelier, que em seus estudos sobre as relações de reciprocidade que se estabelecem a partir das trocas de dons, em que se encerra a tríade "dar", "receber", "retribuir", oferece inspiração decisiva para a compreensão do significado subjacente às trocas que se realizam no âmbito das redes clientelares no antigo regime (effectus por affectus), e que permitem, em outro exemplo, 
a Angela Xavier e António Manuel Hespanha falar em uma "economia moral do dom" para descrever e analisar essas relações. ${ }^{34}$

Talvez o mais imprescindível de se pensar aqui seja como essas racionalidades próprias da ação econômica em seu sentido amplo, desde a subordinação a outras esferas de apreensão da realidade, marcadas por desígnios morais, culturais ou religiosos, até sua autonomização no seio da sociedade de mercado capitalista, constituem um processo que não é linear e absoluto, mas marcado por mediações, permanências e ritmos variados. Neste sentido, a compreensão eminentemente histórica proposta aqui das categorias de clientelismo e patronagem deve ser capturada exatamente na transformação da racionalidade dos atores no que diz respeito a essas trocas pressupostas na relação clientelística.

João Fragoso, em seu Homens de Grossa Aventura, bem como em O Arcaísmo como Projeto, este em co-autoria com Manolo Florentino, vai apresentar uma contribuição decisiva na direção desse raciocínio ao analisar a particular sobreposição de estruturas econômicas diversas que se apresenta às primeiras décadas do Dezenove. Analisando os agentes econômicos centrais desse contexto, os negociantes de grosso trato, foi o autor capaz de surpreender nessa elite econômica uma racionalidade em última instância, ainda que já articulada ao cálculo próprio de mercados integrados como os em que se inseria a praça do Rio de Janeiro no começo do século XIX, marcada pela permanência de categorias sociais próprias do antigo regime, o que levaria esses homens a reproduzirem um projeto arcaizante de hierarquias sociais, negando a reprodução de sua condição de negociante e buscando a inserção em um ideal de nobreza eminentemente ligado à terra. ${ }^{35}$

Esse conjunto de considerações permite a retomada da questão da "cultura política", o outro dos pontos destacados acima como privilegiado para se apreender (surpreender) não o que permanece indistinto no fenômeno clientelístico, mas exatamente o que nele vai se tornando diverso. O conceito de cultura política, ou "culturas políticas", necessariamente inscritas na multiplicidade do plural de práticas e representações como insiste Serge Berstein, ${ }^{36}$ corresponde a uma tentativa de desdobrar a análise das práticas e instituições políticas de modo que incorpore as crenças, os ideais, normas ou tradições que qualificam a vida política em variados contextos. A partir da definição de Giacomo Sani:

(...) compõem a Cultura política de uma certa sociedade os conhecimentos, ou, melhor, sua distribuição entre os indivíduos que a integram, relativos às 
instituições, à prática política, às forças políticas operantes num determinado contexto; as tendências mais ou menos difusas, como, por exemplo, a indiferença, o cinismo, a rigidez, o dogmatismo, ou, ao invés, o sentido de confiança, a adesão, a tolerância para com as forças políticas diversas da própria, etc.; finalmente, as normas, como, por exemplo, o direito-dever dos cidadão a participar da ida política, a obrigação de aceitar as decisões da maioria, a exclusão ou não do recurso a formas violentas de ação. Não se descuram, por último, a linguagem e os símbolos especificamente políticos, como bandeiras, as contra-senhas de várias forças políticas, as palavras de ordem, etc. ${ }^{37}$

Os estudos acerca das culturas políticas somente mais recentemente vêm inquietando os historiadores, tendo merecido a atenção primeira dos cientistas políticos. Isso fez concentrar a maioria dos estudos em que tem destaque esse tipo de análise nos períodos mais recentes. Não obstante, é inequívoca a importância e a necessidade dessas questões aos estudos no campo da história política. Particularmente a contextos em que já se qualifica a dimensão estrutural da ação política na condução do Estado, mas em que ainda não se processou a secularização e racionalização dessas práticas (o caso no antigo regime), a importância que se deve atribuir a esses aspectos "culturais" da vida política é ainda mais crucial. Neste sentido, mesmo destacando essa precedência dos cientistas políticos no uso do termo, alguns dos temas próprios do que na definição de Sani pertencem ao campo da cultura política já são — é necessário que se faça justiça - objetos tradicionais de estudos de historiadores, como no caso das linguagens políticas. Basta aí lembrar os trabalhos de John Greville Agard Pocock e Quentin Skinner, líderes do que já foi descrito como a "Escola de Cambridge" da história do pensamento político, ou ainda, em matriz distinta, nos autores ligados a Geschichtliche Grundbegriffe, o dicionário de "Princípios históricos da linguagem política e social na Alemanha", editado por Otto Brunner, Werner Conze e Reinhart Koselleck. ${ }^{38}$

Por outro lado, é inegável a importância dos avanços da história cultural como guias para a apreensão e análise de determinada cultura política. A discussão dessas questões ultrapassa obviamente as intenções do presente texto; mas ainda assim vale a referência ligeira a um elemento particularmente relevante para essa análise. Trata-se do que na história cultural, particularmente em estudos sobre história da arte, foi se desenvolvendo para permitir a compreensão das concepções e categorias de apreensão da realidade, próprias de determinados contextos históricos. Peter Burke vai se referir a esta dimensão como "esquemas mentais", e neste sentido associa-se a muito do que foi proposto anteriormente por Erwin Panofsky ou Ernst Hans Gombrich. ${ }^{39}$ Associando-se esta dimensão, crucial para a discussão da criação ou da polêmica sobre a idéia de 
progresso nas artes, ao tema do político, é possível caminhar na direção de apreender as práticas e a vida política a partir dos elementos próprios que informavam a percepção própria que os atores políticos tinham de seu universo e das relações de poder nele subjacentes. Avançar para desnaturalizar a prática e pensar como se pensava o político, em dado contexto histórico, ainda que constitua horizonte, por definição, impossível de alcançar, é boa orientação de caminho.

Essa dimensão de análise aplicada às relações de natureza política, próprias da América portuguesa e daí do Brasil independente, oferece eixo para uma interpretação de como, ainda que o traço essencial das relações de poder e de troca política teimem em reforçar a dimensão clientelística, as percepções, estratégias e orientações dos atores políticos vão pouco a pouco assumindo coloridos diversos. Um extenso processo em que é possível marcar reforços de relações de patronagem adquire assim em nossa história política matizes e contornos próprios. Na reprodução de hierarquias sociais próprias do antigo regime na América lusa - ainda que e exatamente por conta dos elementos que marcam a especificidade da formação histórica do contexto americano, no qual assomam, por exemplo, outros ritmos e possibilidades nos caminhos de conformação das elites locais, mesmo que respaldando e se valendo das linguagens e esquemas próprios das referências políticas do antigo regime português — seriam marcantes alguns traços próprios de determinada cultura política como chave para a reprodução de ordem clientelística, aos quais se dará maior atenção à frente. Para além disso, em termos amplos, temas como a progressiva identificação das melhores famílias da terra com o espaço americano na chave das reivindicações pela conquista e a guerra, ou em outro plano as próprias possibilidades de formação de uma identidade colonial indiciada e em gestação no repertório de novos esquemas de reivindicação política, informam diretamente sobre os quadros em que mais propriamente se assentava e a relação clientelística neste momento. ${ }^{40}$ À primeira metade do século XIX, por sua vez, um conjunto de novas referências já passara a conformar muito desses condicionantes políticos mais amplos, e, conseqüentemente, da cultura política própria da prática daqueles atores sociais. Os modelos liberais como elementos-chave do discurso e a contradição, de superfície, entre essas referências e a necessidade de se manter uma estrutura escravista na qual se assentam mesmo as assimetrias sociais são bons exemplos disso.

A República, tempos depois, afloraria de outros conjuntos de tensões políticas, que por sua vez reproduzem tramas clientelísticas, mas, novamente, informadas por 
referências diversas. Os novos atores sociais urbanos (destaquem-se os militares), assim como alterações na base rural (conjuntura de crise econômica no Nordeste), dão corpo a essa realidade. O fenômeno do coronelismo, expressão ícone do clientelismo da República Velha, estudado exemplarmente por Víctor Nunes Leal, é exemplo claro desse contexto e, se comparado às tramas clientelísticas próprias do período colonial, ou as que assomam no segundo reinado, reforçam os padrões gerais, mas deixam revelar significados diversos e estratégias bastante próprias.

A duração alargada de um fenômeno como o clientelismo na política brasileira, passível mesmo de certo avanço em um território já marcado por uma muito mais ampla impessoalização do aparato estatal, como nos dias atuais, em que ainda podem se marcar inúmeras permanências de relações de patronagem no plano político e social, deve ser vista assim na chave de leitura de um processo que combina rupturas e continuidades, e cumpre função essencial, como aponta, por exemplo, João Fragoso, na reprodução de mecanismos de exclusão social. ${ }^{41}$ Talvez o clientelismo, mais propriamente, deva ser encarado, da mesma forma que a cultura política, em seu registro plural. Ainda que entendido aqui como um fenômeno que se reitera ao longo de período muito longo, o clientelismo não compõe de forma alguma, em uma análise política alongada, um "sistema político", e não raro responde a formas por demais variadas, em que se estabelecem as estratégias de ação em conjunturas de forças políticas assimétricas; daí a idéia de não um, mas vários clientelismos. Adiantando a crítica, longe de sabotar a força do conceito, este enfoque ressalta-lhe um traço essencial, a combinação de diferenciação com preservação. Parece válida assim para o clientelismo aquela preciosa chave de análise de que o que nele vai se tornando diverso é exatamente uma forma de preparar a sua reprodução da mesma forma. Ou seja, as relações clientelísticas mudam ao longo do tempo para deixarem iguais as relações sociais assimétricas que estão (e são) na sua própria origem.

\section{O conceito de redes clientelares e a interpretação da política no período colonial}

Estabelecidas essas relações e destacado o sentido em que se pode pensar a duração alargada do fenômeno da patronagem, parece adequado tratar um pouco mais verticalmente das relações clientelísticas próprias do antigo regime e suas tramas na América portuguesa. Segundo Ângela Barreto Xavier e António Manuel Hespanha, as relações clientelares inserem-se no próprio universo mental do antigo regime, 
condicionando as práticas e representações sociais, e conferindo a esse tipo de relação significados culturais distintos do caráter ilegítimo assim como espúrio que a caracteriza hoje:

De facto, relações que obedeciam a uma lógica clientelar, como a obrigatoriedade de conceder mercês aos "mais amigos", eram situações sociais quotidianas e corporizavam a natureza mesma das estruturas sociais, sendo, portanto, vistas como a "norma". A verdade é que estas atitudes foram sendo progressivamente marginalizadas (no sentido inverso ao do progresso do aparelho de "Estado"), até adquirirem o epíteto de corruptas, e são actualmente conotadas como situações de "anormalidade" institucional. ${ }^{42}$

A relação dom e contradom surge assim como elemento central da estruturação das relações políticas no antigo regime, sendo o benefício entendido em esfera muito mais ampla do que a dos ganhos estritamente econômicos, o que só faz aumentar a indefinição dos limites das dívidas que se estabelecem, e que, por sua vez, reforçam os laços que unem os envolvidos. ${ }^{43}$ A natureza dessa relação é diretamente informada pela permanência do conceito aristotélico de "amizade", essencialmente o de "amizades desiguais", tal qual discutido pelo autor em seu Ética a Nicômaco. ${ }^{44}$ A amizade constituiria, neste sentido, o suporte de fortes laços políticos e fonte de deveres duráveis. A amizade na concepção de Aristóteles comporta assim tanto o sentido do amor recíproco entre iguais como também da relação entre desiguais, o que caracterizaria a relação, por exemplo, entre governante e governados, pai e filho ou patrão e cliente. Essas referências informam e povoam as relações políticas no antigo regime português, abrangendo o conceito de amizade "desde as relações entre o rei e os vassalos reciprocamente ligados por laços de amor/amizade (desigual), até as relações filiais (os familiares são simultaneamente os mais amigos) ou de pura amizade (que, quando muito intensa, se assemelharia às relações de família). Esta transposição do imaginário familiar para o campo das relações sociais informais é uma constante da época". ${ }^{45}$ A dualidade entre graça e reciprocidade que enredava as pessoas nessa sociedade cria cadeias e espirais que tendem a ter na figura do rei seu topo. O sistema de mercês delineia esse quadro e tem sua origem em práticas que remontam as guerras pela Reconquista de Portugal contra os muçulmanos na Idade Média. O rei concedia à aristocracia terras e privilégio como recompensa aos serviços prestados à coroa. ${ }^{46}$

A relação que se estabelece a partir da dívida fundada no par liberalidade/gratidão, não obstante, àqueles quadros mentais, assumia a condição de inextinguível. ${ }^{47} \mathrm{O}$ sistema de mercês subordina assim os vassalos como também o 
próprio rei nessas cadeias de gratidão, e é neste sentido o cimento da idéia de redes clientelares. "O rei aparece, assim, sujeito aos constrangimentos e contingências impostos pela economia de favores, e podia ser clara e eficazmente pressionado por determinadas casas poderosas no sentido de tomar esta ou aquela resolução, como, na prática, sucedia com outros actores políticos. ${ }^{\text {,4 }}$ No que tange ao poder real, do século XVII para o XVIII assiste-se a um processo em que progressivamente o rei faz funcionar suas próprias redes para obliterar outras e assegurar a autonomização de seu poder, conferindo às mercês um caráter cada vez mais liberal. Este processo só ganharia corpo efetivamente a partir da legislação pombalina; ainda assim, é importante pensar que no plano social essa arquitetura de poderes teria maior permanência na articulação entre atores de forças políticas desiguais e na aproximação destes às esferas centrais do poder. Isso faz das redes clientelares tema particularmente interessante a contextos que padecem da "distância" do rei, como a América. ${ }^{49}$

A relação clientelística encerra, assim, aos quadros do antigo regime a um só tempo prática social e esquema mental, e em termos efetivos alcança a hierarquização social e a própria administração das diversas partes do império português. A centralidade da idéia de redes clientelares à compreensão da composição de forças políticas e econômicas e da própria conformação das elites na América portuguesa parece assim inquestionável. Não obstante é necessária uma nota de advertência. Ainda que trabalhos como os de João Fragoso possam ser tomados como referências seguras no criterioso rastreamento dessas ligações na América portuguesa e de sua avaliação em quadro conceitual adequado, é fácil ver na historiografia recente a multiplicação de referências um tanto acríticas a tal realidade. Aonde quer que se distinga a parcialidade de certos grupos de interesses, teima-se em ver as "redes" e as relações "clientelares", não distinguindo a especificidade e a dimensão dessas ligações que as fazem próprias para carregarem o título de rede(s) ou o que nelas caracteriza efetivamente o clientelismo. Ou seja, não é certamente toda e qualquer parcialidade de interesses, ou qualquer grupo que constitui uma rede, e não é da mesma forma toda relação desigual que assume a feição clientelar, ainda mais no sentido próprio e agudo que esta assume nos quadros do antigo regime.

Em alguns de seus trabalhos recentes, João Fragoso tem se preocupado em caracterizar como se dá entre os séculos XVI e XVII o que chamou de a montagem da primeira elite senhorial no Rio de Janeiro a partir de expedientes políticos próprios do antigo regime. Marca-se nesses estudos a trajetória de uma "nobreza da terra" que a 
partir "da conquista de terras e de homens (guerras justas, ou não, contra o 'gentio da terra'), do sistema de mercês e domínio da Câmara Municipal, conseguiu se apropriar de parte do excedente da sociedade colonial". ${ }^{50}$ Especificamente se questionando sobre a constituição de capital da economia de plantation fluminense no período, argumenta esse autor:

Trocando em miúdos, a constituição das fortunas daquelas famílias baseou-se na combinação de três práticas/instituição vindas da antiga sociedade lusa: a conquista/guerras - prática que nos trópicos se traduziria em terras e homens, a 'baixos custos', porque foram apossados das populações indígenas; a administração real — fenômeno que lhes dava, além do poder em nome del Rey, outras benesses via sistema de mercês; o domínio da câmara - instituição que lhes deu a possibilidade de intervir no dia-a-dia da colônia.

Provavelmente, esses últimos mecanismos de acumulação e riqueza foram os mais eficazes, já que permitiram a apropriação de recursos não de outro setor particular da economia, mas sim de excedentes regados por toda uma sociedade colonial em formação. ${ }^{51}$

Em termos estritamente econômicos, ainda que dedicando particular atenção ao último tópico anunciado, pode-se dizer que o argumento de Fragoso parece mais frágil no que diz respeito à efetiva demonstração de como se processa essa transferência de parcela de recursos de "toda" essa sociedade colonial em formação, para a formação da plantation fluminense. Sua análise, não obstante, ao investigar as trajetórias familiares dos titulares dessa primeira elite senhorial fluminense, as disputas entre os grupos de interesse (bandos), bem como as ligações e formas de obtenção, a partir de mercês, de posições administrativas e militares naquela sociedade - com todos os privilégios daí decorrentes - , vão desvelando os sentidos próprios em que se faz possível pensar nos termos de redes clientelares à América lusa.

Ainda acompanhando a linha argumentativa de Fragoso, a passagem para o século XVIII representaria um momento particularmente interessante à ampliação desses grupos de interesse que entre disputas e recomposições internas vão se valendo de estratégias clientelares para assegurar posições hegemônicas na sociedade colonial. As descobertas auríferas no interior do continente a partir de 1693 e a rápida ocupação das terras das Minas vão conferindo candidatos entre capitanias para uma teia de alianças parentais com origem nos conquistadores seiscentistas do Rio de Janeiro ou nas melhores famílias da terra paulista à época. ${ }^{52}$ Essas teias de interesse se estenderiam ao longo do século atingindo mesmo os circuitos do aquém-mar e conformando outra vez sentidos próprios do que se pode tratar por redes clientelares. Da mesma forma, outro processo em curso no século XVIII complexificaria essas relações ancoradas antes essencialmente na (auto)definição de direitos próprios de uma nobreza da terra, no sentido de abarcar na hierarquia social os principais envolvidos nos circuitos mercantis que se dinamizavam. Ainda que com distâncias marcadas nas indistinções próprias que carregava a atividade mercantil, nada que já não houvesse encontrado - e o fosse progressivamente - formas de apropriação particulares no pensamento e na sociedade portuguesa, como bem se expressa nas figuras do "mercador-fidalgo" e do "fidalgomercador" analisadas por Vitorino Magalhães Godinho. ${ }^{53}$ Trata-se, objetivamente, do processo que ao longo do século vai dinamizando os circuitos internos produtivos e comerciais da América portuguesa em par com a crescente importância da praça do Rio de Janeiro e dos negócios no Atlântico-sul. De forma ampla isso se traduziria na "lenta 
consolidação de um mercado mais regulado pelos preços e, com ele, a hegemonia dos comerciantes de grosso trato sobre a economia, no lugar da velha nobreza da terra". ${ }^{4}$ Esse processo, não obstante, só teria sua efetivação no século XIX, onde mais explicitamente se verificaria a certa retração do peso da política nos mecanismos centrais de acumulação de riqueza, ante as formas de enriquecimento diretamente ligadas às atividades mercantis. Todo o século XVIII, e especialmente sua primeira metade, ante o eflúvio do ouro na sociedade mineira, assistiria ainda ao peso dessa esfera da política ante a ordem econômica, e a um quadro de forças, bem como a uma composição de elites em que iam imbricados em cadeias supracapitanias e por vezes com ligações transoceânicas, nobreza da terra, comerciantes e mesmo as autoridades metropolitanas. João Fragoso analisa essa conjuntura, refletindo acerca de duas devassas por conta de descaminhos dos tributos do rei, que indiciavam negociantes, nobres da terra e importantes membros da administração real, articulando partes diferentes do império, argumentando como se têm aí:

(...) práticas de acumulação de riquezas derivadas da interferência da política na economia. Parece-me um equívoco resumir estes processos em lutas entre dirigentes corruptos versus a ação de administradores zelosos. Talvez, mais do que isto, tais devassas indiquem enfrentamentos de bandos políticos adversários, tendo por cenário o próprio império luso. Para a sociedade colonial, aquelas práticas de enriquecimento resultavam de uma ordem estamental definida pela política. O seu topo consistia nas melhores famílias da terra, que possuíam poder de mando e, portanto, legitimidade, dada pelos demais segmentos sociais, fenômeno que lhe dava condições de interferir na economia. ${ }^{55}$

Em síntese, estas questões apontam para o peso dos temas da cultura política e da economia à análise das dinâmicas clientelares e, por extensão, à análise crítica aqui defendida dessa reiteração do fenômeno da patronagem ao longo do tempo. Utilizandose assim especificamente do caso aqui referido, no que diz respeito à cultura política como fonte para a reflexão do que especificamente vai se recompondo nas redes clientelares, seria importante o destaque ao sistema de mercês criando espirais de dependências e às estratégias familiares na articulação das redes, ou, ainda, de forma mais ampla, as trocas simbólicas a pesar nas articulações econômicas em um mercado dominado pela esfera da política. Já especificamente no plano da economia, pode-se destacar a importância de uma leitura da mudança, lenta, na própria racionalidade econômica dos atores sociais, o que vai qualificando novas possibilidades de inserção na estrutura da sociedade e sua complexificação, visível com particular clareza em contextos de rápida expansão urbana como no caso das Minas Gerais setecentistas.

CUNHA, Alexandre Mendes. Patronage, Clientele, and Political Networks: the apparent duration of a concept within Brazilian political history. História, São Paulo, v. 25, n. 1, p. 226-247, 2006. 
Abstract: The article aims to discuss the reiteration of clientelistic relationships in Brazilian political history. It critically discusses the apparent long duration of the clientelistic relationships since colonial until republican times. The main point is understanding how the changes in these relationships are part of a continuity strategy. Two analytical dimensions are suggested with this purpose: the forms of economical rationality and the culture of politics.

Keywords: clientelistic relationships, historiography, political history.

Artigo recebido 09/2006. Aprovado em 11/2006.

${ }^{1}$ Trabalho realizado com o apoio do Conselho Nacional de Desenvolvimento Científico e Tecnológico (CNPq).

Núcleo de Pesquisa em História Econômica e Demográfica, Cedeplar/UFMG (Rua Curitiba, 832 Belo Horizonte / MG / Brasil - 30170-120). Registro meu agradecimento às considerações apresentadas pelo parecerista anônimo que avaliou o artigo.

2 BRAUDEL, Fernand. História e Ciências Sociais: a longa duração. In: Escritos sobre a história. São Paulo: Perspectiva, 1978; WALLERSTEIN, Immanuel. O homem da conjuntura. In: AYMARD, Maurice (org.). Ler Braudel, Campinas (SP): Papirus, 1989.

${ }^{3}$ Uma análise criteriosa e recente acerca do tema do iberismo pode ser encontrada em: BARBOZA FILHO, Rubem. Tradição e Artifício: Iberismo e Barroco na Formação Americana. Belo Horizonte, Ed. UFMG, Rio de Janeiro: IUPERJ, 2000.

${ }^{4}$ VIANNA, Luiz Weneck. Weber e interpretação do Brasil. Novos Estudos CEBRAP, São Paulo (53), março de 1999, p. 35; ALONSO, Angela. Império da Patronagem. Novos Estudos CEBRAP, São Paulo (49), novembro de 1997, pp. 231-2.

5 Ver DUARTE, Nestor. A ordem privada e a organização política nacional. São Paulo: Companhia Editora Nacional, 1939.

6 CARVAlHO, José Murilo de. Mandonismo, Coronelismo, Clientelismo: uma discussão conceitual. DADOS - Revista de Ciências Sociais, Rio de Janeiro, v. 40, n. 2, p. 241; MARX, Karl. Formações econômicas pré-capitalistas. 3. ed., Rio de Janeiro: Paz e Terra, 1981; WEBER, Max. Economia e sociedade: fundamentos da sociologia compreensiva. Brasília: Editora UnB, 1999. [vol.2, capítulo IX Sociologia da dominação (seção 3 - Dominação patriarcal e dominação patrimonial, e seção 4 Feudalismo, 'Estado corporativo' e patrimonialismo)]

7 VIANNA, Luiz Weneck. Weber e interpretação..., p. 35.

${ }^{8}$ Ver TAVARES BASTOS, Aureliano Candido. A província: estudo sobre a descentralisação no Brazil. 2. ed., São Paulo: Companhia Editora Nacional, 1937; SARMIENTO, Domingo Faustino; POMER, Leon. D. F. Sarmiento: política. São Paulo: Ática, 1983; SARMIENTO, Domingo Faustino. Civilización y barbarie: trilogía de Quiroga-Aldao - El Chacho mi defensa recuerdos de província. Buenos Aires: El Ateneo, 1952.

${ }^{9}$ VIANNA, Luiz Weneck. Weber e interpretação..., p. 35.

10 Idem.

11 Idem, p.38.

12 NOVAIS, Fernando. O significado da "Guerra do Paraguai" na História do Brasil. In: MARQUES, Maria Eduarda Castro Magalhães (org.). A Guerra do Paraguai - 130 anos depois. Rio de Janeiro: Relume Dumará, 1995, p. 79.

13 GRAHAM, Richard. Clientelismo e política no Brasil do século XIX. Rio de Janeiro: Editora UFRJ, 1997

14 NAMIER, Sir Lewis. The Structure of Politics at the accession of George III. 2. ed. London: The Macmillan Press, 1957.

${ }^{15}$ GRAHAM, Richard. Clientelismo..., pp. 76-82. 
16 MATTOS, Ilmar Rohloff de. O tempo saquarema: a formação do Estado imperial. Rio de Janeiro: Access, 1994.

17 GRAHAM, Richard. Construindo uma nação no Brasil do século XIX: visões novas e antigas sobre classe, cultura e Estado. Revista Diálogos, v. 1(5), 2001.

18 Idem.

19 GRAHAM, Richard. Clientelismo e política..., p. 82.

20 Ver ELIAS, Norbert A Sociedade de Corte: investigação sobre a sociologia da realeza e da aristocracia de corte. Rio de Janeiro: Jorge Zahar, 2001.

21 ALONSO, Angela. Império..., p. 233.

22 CARVALHO, José Murilo de. A Construção da Ordem: a elite política imperial. Teatro das Sombras: a política imperial. Rio de Janeiro: Civilização Brasileira, 2003.

23 CARVALHO, José Murilo de. Mandonismo..., pp. 242-243.

24 Ver CLAPHAM, Christopher. Clientelism and the State. In: CLAPHAM, Christopher (ed.). Private Patronageand Public Power. Political Clientelism in the Modern State. London: Frances Pinter Publ., 1982.

25 CARVALHO, José Murilo de. Mandonismo ..., p. 242.

${ }^{26}$ Ver LEAL, Victor Nunes. Coronelismo, Enxada e Voto. Rio de Janeiro: Forense, 1948.

27 ALONSO, Angela Império..., p. 234.

28 Idem.

29 XAVIER, Ângela Barreto; HESPANHA, António Manuel. Redes Clientelares. In: HESPANHA, António Manuel (coord.). História de Portugal. Lisboa: Editorial Estampa, 1993, v. 4, p. 381

${ }^{30}$ PAULA, João Antônio de. O mercado e o mercado interno no Brasil: conceito e história. História Econômica \& História de Empresas, ABPHE, v. 1 (2002), p. 8; cf. também XAVIER, Ângela Barreto; HESPANHA, António Manuel. A representação da sociedade e do Poder. In: HESPANHA, António Manuel (coord.). História de Portugal. Lisboa: Editorial Estampa, 1993, v. 4.

31 THOMPSON, E. P., A economia moral da multidão inglesa no século XVIII e A economia moral revisitada. In: Costumes em comum: estudos sobre a cultura popular tradicional. São Paulo: Companhia das Letras, 1998. Essa linha de leitura insere mesmo E. P. Thompson como influência importante no debate clássico sobre a transição do feudalismo para o capitalismo, uma vez que coloca o avanço das relações de mercado como diretamente conformando pelos conflitos sociais. O progressivo efeito de dimensões análogas a esta na composição de uma nova racionalidade econômica é estudado exemplarmente por Robert Brenner, e mais recentemente retomado por Ellen Wood em seus estudos. [BRENNER, Robert. Merchants and revolution: commercial change, political conflict and London's overseas traders, 1550-1653. Cambridge, Cambridge University, 1993; ASTON, T. H.; PHILPIN, C. H. E. (orgs.). The Brenner debate: agrarian class structure and economic development in pre-industrial Europe. Cambridge: Cambridge University Press, 1985; Ellen WOOD, Meiksins. A origem do capitalismo. Rio de Janeiro: Jorge Zahar, 2001.

32 POLÁNYI, Karl. A grande transformação: as origens da nossa época. Rio de Janeiro: Campus, 1980; IDEM. A nossa obsoleta mentalidade mercantil. Revista Trimestral de Letras e Idéias. Porto: Afrontamento, 1978; MARX, Karl. O Capital: crítica da economia política. Livro I, Rio de Janeiro: Civilização Brasileira, 1998; Wood, Ellen. A origem..., p. 29.

33 PAULA, João Antônio de. O mercado..., p. 9.

34 MAUSS, Marcel. Essai sur le don. In: Sociologie et anthropologie. Paris, PUF, Quadrige, 1997, pp. 145-279; XAVIER, Ângela Barreto; HESPANHA, António Manuel. Redes Clientelares, v. 4, p. 386.

35 MARX, Karl. Formações econômicas..., 1981; FRAGOSO, João. Homens de Grossa Aventura: acumulação e hierarquia na praça mercantil do Rio de Janeiro (1790-1830). 2. ed. rev. Rio de Janeiro: Civilização Brasileira, 1998; FRAGOSO, João. FLORENTINO, Manolo. O Arcaísmo como Projeto: mercado atlântico, sociedade agrária e elite mercantil no Rio de Janeiro, c.1790 - c.1840. Rio de Janeiro: Sette Letras, 1998.

36 BERSTEIN, Serge. La culture politique. In: RIOUX, Jean-Pierre. SIRINELLI, Jean-François (dir.). Pour une histoire culturelle. Paris: Éditions du Seuil, 1995.

37 SANI, Giacomo. Cultura Política. In: BOBBIO, Norberto; MATTEUTTI, Nicola; PASQUINO, Gianfranco. Dicionário de Política. Brasília: Ed. UNB, 1995, p. 306.

38 Cf. POCOCK, John Greville Agard. Linguagens do ideário político. São Paulo: Edusp, 2003; SKINNER, Quentin. As fundações do pensamento político moderno. São Paulo: Companhia das Letras, 
1996; RICHTER, Melvin. Reconstructing the History of Political Languages: Pocock, Skinner and the Geschichtliche Grundbegriffe. History and Theory. Middletown, 29(1): 38-70, 1990 e BRUNNER, Otto. CONZE, Werner (orgs.). Geschichtliche grundbegriffe: historisches lexikon zur politisch-sozialen sprache in Deutschland. Stuttgart: Klett-Cotta, 1984, 7v.

39 Ver PANOFSKY, Erwin. Significado nas artes visuais. 2. ed. São Paulo: Perspectiva, 1979 e GOMBRICH, Ernst Hans. Arte e ilusão: um estudo da psicologia da representação pictórica. São Paulo: Martins Fontes, 1986.

40 Sobre a dimensão da identidade colonial veja especialmente: FIGUEIREDO, Luciano Raposo de Almeida. Revoltas, fiscalidade e identidade colonial na América portuguesa: Rio de Janeiro, Bahia e Minas Gerais, 1640-1761. São Paulo: FFLCH/USP, 1996. Tese de Doutorado em História.

${ }^{41}$ FRAGOSO, João. Para que serve a história econômica? - Notas sobre a história da exclusão social no Brasil. Estudos Históricos, Rio de Janeiro (29), 2002.

42 XAVIER, Ângela Barreto; HESPANHA, António Manuel. Redes Clientelares, v. 4, p. 381.

43 Idem, p. 382.

44 ARISTÓTELES. Ética a Nicomacos, tradução do grego, introdução e notas de Mário da Gama Kury, Brasília, Ed. Universidade de Brasília, 1985.

45 Idem, p. 385.

46 Sobral Neto, Margarida. A persistência senhorial. In: MAGAlhães, Joaquim Romero de (coord.). História de Portugal. Lisboa: Editorial Estampa, 1993, v. 3, p. 165; FRAGOSO, João. A formação da economia colonial no Rio de Janeiro e de sua primeira elite senhorial (sécs. XVI e XVII). In: FRAGOSO, João; BICALHO, Maria Fernanda; GOUVÊA, Maria de Fátima. O Antigo Regime nos Trópicos: a dinâmica imperial portuguesa (séculos XVI-XVIII). Rio de Janeiro: Civilização Brasileira, 2001, p. 43; FRAGOSO, João; GOUVÊA, Maria de Fátima; BICALHO, Maria Fernanda Baptista. Uma leitura do Brasil colonial: bases da materialidade e da governabilidade no Império. Penélope, fazer e desfazer a história, Lisboa (23), , p. 68, 2000.

47 XAVIER, Ângela Barreto. HESPANHA, António Manuel. Redes Clientelares, v. 4, p. 390.

48 Idem, p. 392.

49 Para considerações acerca da dimensão da "distância" no plano da política colonial, cf. FIGUEIREDO, Luciano Raposo de Almeida. Revoltas, Fiscalidade e Identidade Colonial..., pp. 275-313 e em outra perspectiva RUSSEL-WOOD, A. J. R. Centros e periferias no mundo luso-brasileiro, 1500-1808. Revista Brasileira de História, São Paulo, v. 18 (36), 1998.

50 FRAGOSO, João. Para que serve a história econômica?..., p. 12; FRAGOSO, João. A formação da economia..., pp. 51-61.

${ }^{51}$ FRAGOSO, João. A formação da economia..., pp. 42-43.

52 FRAGOSO, João. Elites econômicas em finais do século XVIII: mercado e política no centro-sul da América lusa. Notas de uma pesquisa. In: JANCSÓ, István (org.). Independência: História e Historiografia, São Paulo: Hucitec, 2005.

53 Ver GODINHO, Vitorino Magalhães. Estrutura da antiga sociedade portuguesa. Lisboa: Arcádia, 1975; e também, para uma análise voltada para as Minas setecentistas, FURTADO, Júnia Ferreira. Homens de negócio: a interiorização da metrópole e do comércio nas Minas setecentistas. São Paulo: Hucitec, 1999.

${ }^{54}$ FRAGOSO, João. Para que serve a história econômica?..., p. 13; ALENCASTRO, Luís Felipe. $O$ trato dos viventes: formação do Brasil no Atlântico sul, sécs. XVI e XVII. São Paulo: Companhia das Letras, 2000.

55 FRAGOSO, João. Elites econômicas..., cit. 